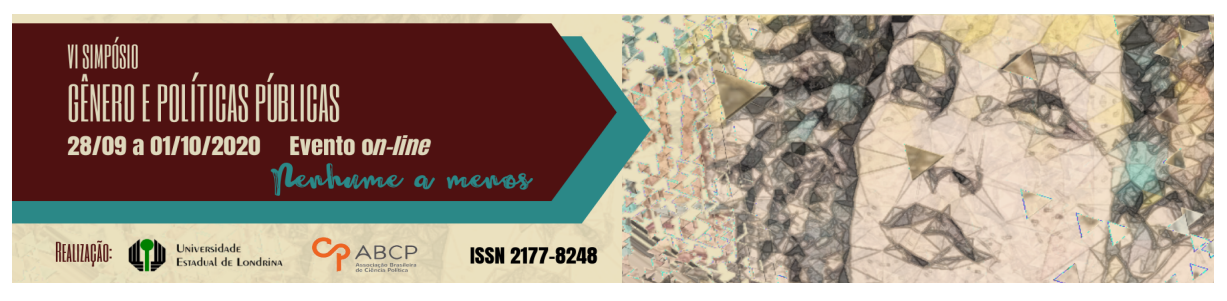

\title{
Movimentos sociais e Estado: a representação das mulheres no Brasil e no México
}

\author{
Anne Karoline Rodrigues Vieira ${ }^{1}$
}

\section{Resumo}

Este trabalho faz uma análise da relação de governos em dois países diferentes com movimentos sociais - feministas e conservadores - para uma abertura ou não do debate em torno de políticas para as mulheres. O período de análise corresponde aos governos do PRI e do PAN no México e o governo do PT no Brasil. Os casos desses dois países nos chamam a atenção; como em um país que possuía um governo de esquerda no Executivo e uma aproximação com os movimentos feministas, não foi capaz de avançar em algumas áreas de políticas para as mulheres; enquanto o outro, que não apresenta todos esses fatores e contava com um governo conservador/pragmático no nível federal, conseguiu avançar em determinadas questões? Esta é uma temática que merece atenção pelo fato de que a representação de gênero, nos países estudados, difere do que é esperado pela literatura e, com isso, o estudo visa mostrar o que precisa ser compreendido desses casos.

Palavras-chave: gênero; grupos conservadores; movimentos feministas.

\section{Social movements and the State: the representation of women in Brazil and Mexico}

\begin{abstract}
This paper analyzes the relationship between governments in two different countries with social movements - feminist and conservative - for an opening or not of the debate around policies for women. The period of analysis
\end{abstract}

\footnotetext{
${ }^{1}$ Ipol/UnB. Doutoranda em Ciência Política pela Universidade de Brasília. Graduada em Ciências Sociais (Unimontes) e mestre em Ciência Política (UnB). E-mail: annervieira@gmail.com; ORCID: https:// orcid.org/0000-0002-3609-7786.
}

GT 13 - Gênero, participação e representação política 
corresponds to the PRI and PAN governments in Mexico and the PT government in Brazil. The cases of these two countries call our attention; as in a country that had a left-wing government in the executive and an approach to feminist movements, it has not been able to advance in some policy areas for women; while the other, which does not have all of these factors and had a conservative / pragmatic government at the federal level, managed to advance on certain issues? This is an issue that deserves attention due to the fact that gender representation in the countries studied differs from what is expected by the literature and, with this, the study aims to show what needs to be understood in these cases.

Keywords: Conservative groups, feminist movements, gender.

\section{Introdução}

As questões de gênero são exemplos de direitos que ganharam importância em toda América Latina nos últimos anos. É possível citar a legalização do aborto no Uruguai e no estado mexicano de Oaxaca. Contudo, esta temática não deixa de apresentar controvérsias, barreiras e reações (SÁEZ; FAÚNDES, 2016). Isso ocorre porque, segundo Htun e Weldon (2010, p. 207), as políticas de igualdade de gênero buscam mudanças significativas "e, portanto, desafiam os padrões históricos de interação estado-sociedade" 2 .

Sob esse cenário, este trabalho analisa dois países em períodos que possuíam contextos políticos diferentes. Nos governos conservadores/pragmáticos do México entre 2000 e 2018, em nível federal, o Legislativo - que possui um número considerável de mulheres - tinha relativos avanços das políticas de gênero, como a aprovação da lei da paridade. Enquanto isso no Brasil, governado entre 2003 a 2016 - por um partido progressista, com uma forte relação com movimentos sociais e que formava uma coalizão majoritária no Legislativo - o qual possui um dos piores índices de participação de

2 Tradução livre do inglês: "seek fundamental social change and therefore challenge historical patterns of state-society interaction" (HTUN; WELDON, 2010, p. 207). 
mulheres do continente -, políticas voltadas para a igualdade de gênero encontraram algumas dificuldades para serem aprovadas.

Para esta análise, foca-se na relação entre os movimentos feministas e os conservadores com o Estado na tentativa de apresentar ou rejeitar políticas de gênero. Eles se mostram importantes porque são dois atores que podem influenciar os diferentes avanços e retrocessos na agenda de igualdade de gênero.

O artigo está estruturado da seguinte maneira: primeiramente é apresentado, de forma breve, os dois países e como cada um lidou com as questões de gênero. Além disso, são apresentados pontos, colocados pela literatura, que mostram o que leva a uma atuação de gênero. Em seguida se trabalha a relação dos movimentos feministas com o Estado e o que isso poderia influenciar na atuação para as mulheres. Posteriormente, é apresentada como a relação entre o Estado e os grupos conservadores podem servir de obstáculos para essa atuação. Por fim, são apresentadas as considerações finais.

\section{Avanços e retrocessos no Brasil e no México}

Embora haja grande diferença entre os países do ponto de vista da presença de mulheres no parlamento, o México alcançando a paridade em 2015 e Brasil chegando a 15\% apenas em 2018, este não parece ser o único fator a explicar os avanços no primeiro. Ao mesmo tempo que houve um avanço na agenda de gênero, durante os governos conservadores do México, observa-se a apresentação de demandas contra o aborto e a favor da família, não podendo ser descartado confrontos entre as ativistas femocratas e as conservadoras. Um exemplo de política adotada nesta época é a "Lei Geral de Acesso das Mulheres por uma Vida Livre", voltada para o combate da violência contra as mulheres, um tema que não gera muitos conflitos entre as mais diversas ideologias e que foi construído dentro do parlamento por algumas deputadas feministas. Devido ao contexto de crescente violência no país, principalmente a partir de 2006, leis mais 
progressistas foram apresentadas por ativistas feministas e encontraram apoio nos três poderes (ZAREMBERG; ALMEIDA, no prelo). Com isso, se observa que no México há um avanço em políticas relacionadas com a igualdade política e direitos sexuais e reprodutivos, temas considerados polêmicos e de difícil aprovação.

Já no Brasil, identifica-se a não aprovação de projetos de lei como o PL n ${ }^{\circ}$ 4211/2012, intitulado Gabriela Leite, que versava sobre a regulamentação da atividade dos profissionais do sexo, tema que pode ser considerado bastante controverso, até mesmo para o movimento feminista. Enquanto se concretizava a aprovação da Proposta de Emenda à Constituição - PEC das Domésticas, no 66/2012, que equiparou os direitos trabalhistas de empregadas/os domésticas/os aos dos trabalhadores formais, e da Lei 12845/2013, que dispõe sobre o atendimento às vítimas de violência sexual. Ainda, como uma das principais referências de políticas para as mulheres, está o Bolsa Família. Este programa confere autonomia para as mulheres ao garantir a elas a responsabilidade pelo recebimento do auxílio financeiro. Desta forma, no país, há a aprovação de políticas mais vinculadas com direitos trabalhistas e de distribuição de recursos, sendo que temas mais polêmicos apresentam dificuldades de tramitação.

Alguns autores já se debruçaram em torno da questão do que leva os governos a atuarem em questões de gênero. Segundo Rodríguez Gustá e Madera (2016), as ações legislativas em torno dos direitos das mulheres podem ser o resultado da convergência de representantes motivados, lobby de organizações sociais e o suporte das Nações Unidas.

Observando a reforma pró-aborto na América Latina, Blofield e Ewig (2017) apontam que ela é influenciada por questões específicas, são elas: a opinião pública, o nível de secularização, a força da mobilização das feministas em oposição à mobilização dos conservadores e a ideologia do governo. Isso mostra que não se pode apenas considerar o partido que está no poder quando se pretende analisar a implementação ou não deste tipo de política. Contudo, as autoras reforçam que partidos de esquerda são uma condição necessária 
para a aprovação de políticas vinculadas ao gênero, principalmente o aborto.

Isso nos leva a considerar o parlamento mexicano como um caso desviante em que, sob partidos de direita, se conseguiu aprovar algumas medidas pró-gênero, dentre elas a paridade, que permitiu ao país ter uma alta representação de mulheres no Legislativo nacional. Este fato é ainda mais importante ao se constatar que a América Latina possui índices muito baixos de mulheres representantes.

Outro ponto que é ressaltado pelas autoras acima citadas - e que nos chama a atenção ao olharmos os casos aqui selecionados - é que partidos de esquerda institucionalizados são os mais propensos a avançar em questões de gênero mais polêmicas. Entretanto, o PT Partido dos Trabalhadores, considerado um partido institucionalizado, não apresentou essa capacidade apontada pelas autoras de avançar em determinadas políticas de gênero.

Ainda, é ressaltado na pesquisa realizada por Blofield e Ewig (2017), que os governos que não são progressistas têm a tendência de defender o status quo ou de promover reformas mais conservadoras. $\mathrm{O}$ México, em nível estadual e municipal, é um dos países considerados pelas autoras. Elas apontam que se observam políticas de restrição ao aborto em alguns lugares do país, enquanto em outros - como no Distrito Federal, sob o governo do Partido de la Revolución Democrática (PRD) - foi permitido, sob algumas condições. Apesar de não ter aprovado o aborto legal no nível federal, o México avançou de forma progressista em algumas questões de igualdade de gênero, como na paridade e no combate à violência contra a mulher, o que nos leva a relativizar o argumento das autoras em relação à produção de políticas conservadoras por países governados pela direita.

Os movimentos feministas como influenciadores na atuação para mulheres 
De acordo com Weldon (2011), movimentos fortes e autonômos de mulheres garantem uma maior capacidade aos governos na atuação às questões das mulheres. Para a autora, tais movimentos exercem um papel importante para a representação substantiva feminina, uma vez que um movimento forte "melhora as capacidades institucionais do governo no enfrentamento das questões das mulheres" (WELDON, 2002, p. 1162) ${ }^{3}$.

Com a entrada no Estado, estes movimentos conseguiram ter as suas demandas ouvidas, mas também conseguiram, segundo Pinheiro (2015), alterar parcialmente a estrutura estatal ao aprofundarem a democracia. Serem incluídos é a meta dos movimentos sociais em toda América Latina, como aponta a autora, incluindo os dois países aqui estudados. Para isso, eles buscam diversos meios, como canais de participação, a entrada no Estado ou até mesmo a candidatura para cargos eletivos.

No Brasil, a prática desses movimentos “[...] tem levado cada vez mais os mesmos a se voltarem para o Estado como ponto de referência para a sua atuação, seja fora ou dentro dele" (PINHEIRO, 2015, p. 44). Se observam importantes medidas que poderiam garantir uma maior aproximação entre as feministas e o Estado, o que permitiria a introdução das demandas de gênero neste último. Como exemplo, a Constituição Brasileira de 1988 garantiu a organização de conselhos e conferências, o que estabeleceu uma democracia participativa no país (PINHEIRO, 2015), cabendo ressaltar que o CNDM - Conselho Nacional dos Direitos da Mulher foi criado antes. Já entre 2003 e 2015 se verifica um aprofundamento nos processos participativos que são vistos no Brasil desde a redemocratização. Há o surgimento ou o fortalecimento de instituições que tinham como objetivo permitir a participação da sociedade. Isso ocasionou, segundo Matos (2016), a elaboração de uma quantidade significativa de políticas que visavam os grupos subalternos. O cenário, entretanto, é diferente para as instituições

3 Tradução livre do inglês: "improve[s] the institutional capabilities of government in addressing women's issues" (WELDON, 2002, p. 1162). 
voltadas para as políticas para as mulheres. Entre 1990 e 2003 poucos Conselhos Estaduais de Mulheres existiam ou eram ligeiramente institucionalizados, enquanto o Conselho em nível nacional tinha perdido força.

Foi durante o governo do PT que o Conselho Nacional dos Direitos da Mulher (CNDM) foi reformulado e passa a ser baseado na representação de organizações, como os outros conselhos de políticas, o que garantiria uma maior absorção das demandas feministas; e as Conferências Nacionais para as Mulheres tiveram início, se tornando mais uma alternativa dos movimentos para interagirem de forma direta com o Estado (PINHEIRO, 2015). As Conferências se mostram importantes, porque, segundo o estudo realizado por Pogrebinschi e Santos (2011), elas têm impactado na formação da agenda do Legislativo, beneficiando, principalmente, os grupos historicamente excluídos. Muito do que foi aprovado dentro do Congresso tinha como referência temas abordados nessas conferências. Desta forma, o conselho e as conferências aproximaram os grupos feministas dos espaços de decisão política.

Entretanto, Rodríguez Gustá et al (2017) captam, de diversos atores sociais, que o trabalho junto ao governo do PT, em alguns momentos, era caracterizado pela inércia - uma vez que algumas demandas do movimento não eram consideradas ou demoravam para serem debatidas - e as questões conflituosas tinham certa dificuldade de tramitação. Outro ponto importante é que esta aproximação dos movimentos feministas com o Estado no Brasil deve ser lida sob a chave da aproximação com o Executivo 4 e muito dependente dos laços com o PT (ZAREMBERG; ALMEIDA, no prelo), o que pode ter dificultado a relação com o Legislativo e o avanço das políticas neste poder. Não se considera, entretanto, que esta dependência possa ser caracterizada

\footnotetext{
4 Não é descartado, contudo, o papel importante exercido pelo Legislativo neste período. Este poder também abriu espaço para as feministas e foi o responsável pela iniciativa de algumas propostas de lei voltadas para as mulheres. Já em relação ao Judiciário não se observa, no Brasil, uma forte relação dele com as feministas, como será apontado no caso mexicano.
} 
como cooptação, mas se acredita que a proximidade entre esses dois atores dificultava ao movimento feminista a construção de uma oposição a certos posicionamentos do PT, já que foi esse partido que ampliou os espaços para as feministas.

Cabe ressaltar, também, que vem sendo observado um papel de bloqueio das ações conservadoras, por parte do movimento feminista no país (ZAREMBERG; ALMEIDA, no prelo). Isso se caracteriza pela atuação no Congresso, contestando o conteúdo de políticas que possuem o caráter de retrocesso nos direitos femininos - impedindo ou atrasando o andamento da política. O principal exemplo desta atuação é em relação ao Estatuto do Nascituro que dispõe sobre a proteção integral do nascituro, dando a ele personalidade jurídica desde a concepção, podendo impedir o aborto. Proposto em 2005, este projeto de lei vem sendo pautado constantemente no Congresso Nacional, mas devido à forte pressão do movimento feminista, até hoje não foi aprovado.

O movimento feminista mexicano tem uma participação destacada no país a partir do novo regime pós-revolucionário, momento em que passou a demandar a inserção do mesmo nas estruturas de poder (IBARRA GARCÍA; DAMIÁN BERNAL, 2013). Durante o governo do PRI - Partido Revolución Institucional, que ficou no poder durante 70 anos ininterruptos, o que se viu foi a cooptação das mais diversas organizações sociais, dentre elas os movimentos feministas. Com o retorno da alternância democrática, a partir dos anos 2000, o que se observou foi a desconfiança, por parte dessas organizações, que viam as promessas de crescimento dos espaços de participação não serem cumpridas (ZAREMBERG; GUZMÁN LUCERO, 2019).

No entanto, a partir da participação na transição democrática no México, as feministas do país passaram a ocupar posições dentro das três esferas de poder. Desta forma, as redes de ativistas feministas demonstraram, na esfera federal, uma grande capacidade de influência. No Legislativo, criaram o Parlamento Feminino (Legislatura LVII 1997/2000), comissão e mecanismo participativo que reunia as duas 
casas legislativas, e na legislatura seguinte o que se constatou foi uma aproximação entre as legisladoras e o Instituto Nacional das Mulheres - Inmujeres. Este Instituto foi criado em 2001 e conta também com institutos semelhantes nos âmbitos estaduais. Assim, o México é, igualmente, um exemplo de um país em que os movimentos feministas lutaram para conseguir a criação de instituições dentro do Estado que permitissem a implementação de políticas voltadas para as mulheres (ZAREMBERG; GUZMÁN LUCERO, 2019).

Além do mais, logo após a eleição ocorrida em 2000, diversas organizações de mulheres e candidatas assinaram o "Acuerdo entre Mujeres para una Agenda Legislativa y Regla de Gobierno a favor de la Equidad". Segundo Rodríguez Gustá et al. (2017, p. 471), com esse acordo as feministas buscavam influenciar a agenda do governo em qualquer iniciativa relacionada à reforma estatal.

Vale ressaltar que o avanço da agenda de gênero no México acontece exatamente no momento da alternância partidária, período considerado como de transição democrática no país e mesmo período de criação do Inmujeres, ocasião em que diversas medidas pró-gênero foram adotadas, mesmo que tenham sido tomadas em um governo considerado conservador/pragmático. As ativistas femocratas vão apresentar um papel importante para o avanço da agenda de gênero neste período no país (ZAREMBERG; ALMEIDA, no prelo).

Apesar de que o início da relação entre congressistas e a presidência do Inmujeres não tenha sido tranquila, se observou que a articulação entre esses dois atores passou a ser muito importante.

Assim, essa rede de ativistas situada tanto dentro do Executivo quanto no Legislativo conseguiu controlar o avanço da agenda conservadora dentro do INMUJERES. O segundo presidente do INMUJERES, também do PAN, teve um perfil progressista e reconstruiu a relação com a rede de mulheres ativistas do Legislativo. Finalmente, o terceiro presidente, do PRI, se afastaria de algumas redes ativistas, mas manteria uma relação positiva com as 
congressistas e senadores ALMEIDA, no prelo, p. 7) ${ }^{5}$.

(ZAREMBERG;

Zaremberg e Guzmán Lucero (2019) apontam a importância de mulheres com diversas trajetórias entre Estado e movimentos para impedir o avanço de políticas conservadoras. Isso reforça a ideia de que os movimentos sociais podem adotar estratégias de luta a partir de dentro do Estado. Ainda, esta ideia de "múltiplas trajetórias, inspirado na análise das redes, está associado ao dos repertórios socioestaduais que atuam como antídoto à rígida ideia de cooptação" (ZAREMBERG; GUZMÁN LUCERO, 2019, p. 150)'dos movimentos sociais. No caso do México, se observa também uma conexão entre os movimentos feministas e o Judiciário, pois foi neste espaço que as mulheres conseguiram a concretização e aprofundamento de diversos direitos, dentre eles a devida execução da lei de cotas. Desta forma, se afirma que os movimentos feministas podem integrar diversos espaços sociais ao longo de suas tragetórias de atuação.

Possuindo posições estratégicas na rede, as mulheres podem influenciar as políticas (ZAREMBERG; GUZMÁN LUCERO, 2019). Isso ocorre porque essas feministas, com uma rede ampla, conseguem estabelecer relações com atores legislativos e negociar as políticas com eles. Isso acaba demostrando a importância que tem as femocratas na atuação para as mulheres.

Apesar do avanço nessas pesquisas que apontam os resultados positivos da interação socioestatal, a inserção de integrantes de movimentos feministas nas estruturas do Estado traz de volta o debate sobre autonomia ou não em relação aos partidos. A falta de

\footnotetext{
5 Tradução livre do inglês: “Thus, this network of activists situated both within the executive as well as in the legislature were able to control the advance of the conservative agenda within INMUJERES. The second INMUJERES president, also from the PAN, had a progressive profile and rebuilt the relationship with the network of women activists of the Legislature. Finally, the third president, from the PRI, would move away from some activist networks but maintain a positive relationship with the congresswomen and senators" (ZAREMBERG; ALMEIDA, no prelo, p.7).

6 Tradução livre do espanhol: "trayectorias múltiples, inspirado en el análisis de redes, se acopla al de repertorios socio-estatales actuando como antídoto frente a la idea rígida de cooptación" (ZAREMBERG; GUZMÁN LUCERO, 2019, p.150).
} 
organizações autônomas, em um momento em que aquelas mais importantes estão dentro do Estado, leva ao risco de perda de influência. Com isso, não apenas a existência desses grupos importa para influenciar a adoção de uma política, mas também a autonomia deles. Deve-se considerar que a inclusão realizada pelo Estado pode ser superficial, impedindo que movimentos sociais tenham uma capacidade crítica e moderem o seu ativismo e suas reivindicações para continuar tendo acesso ao Estado (Ibid., 2011).

Citando estudo realizado por Dryzek entre outros pesquisadores, Weldon (2011) aponta que alguns Estados que incluem movimentos sociais, acabam esgotando a sociedade civil. Essa discussão também ocorre no interior dos movimentos que questionam se deveriam ou não "[...] lutar para que as mulheres ocupassem postos de comando e disputassem eleições nas democracias" (BLOFIELD et al, 2017, p. 14), exigindo a aprovação e devida implementação de ações afirmativas - como as leis de cotas - no processo eleitoral, sendo que algumas feministas se mostram contrárias à adoção de cotas. Entretanto, Weldon (2011) ressalta que apenas o fato de participar da formulação de políticas não caracteriza a cooptação nem a despolitização destes movimentos.

Essas questões apresentadas podem influenciar, de alguma maneira, nos resultados de políticas para as mulheres nos dois países. $\mathrm{O}$ PT foi constituído abarcando diversos ativistas, entre os quais alguns chegaram a assumir cargos na burocracia estatal durante o governo. Ao assumir o poder e garantir a participação das feministas no seu governo, das mais variadas formas, apresenta indícios de que não incluiu de forma plena as demandas destes movimentos.

Ainda, cabe-nos questionar se a relação entre movimentos sociais e Estado, mais especificamente dos movimentos feministas no México, é o que proporcionou o crescente número de políticas para as mulheres, mesmo em um governo de direita. Uma vez que o giro à esquerda foi uma janela de oportunidades para esses movimentos em outros países da região, no qual “Contribuíram para isso a afinidade de 
muitos militantes com forças de esquerda, o apoio mais homogêneo de setores progressistas a reformas semelhantes ou a ideia de que seriam governos mais sensíveis para responder sobre questões de igualdade" (PÉREZ BENTANCUR; ROCHA CARPIUC, no prelo, p. 24)7, qual seria a janela de oportunidades no México? Diferente do que aconteceu no Brasil, as feministas mexicanas se aproximaram também dos partidos conservadores, o que nos leva a pensar nas relações que esses movimentos promoviam e com quais tipos de atores.

\section{A influência conservadora na América Latina}

Blofield e Ewig (2017) apontam que a Igreja Católica e os grupos conservadores têm sido mais influentes e organizados do que os movimentos feministas, contando com relações diretas com as elites políticas. Assim, a agenda de gênero pode apresentar obstáculos para a sua aprovação devido às ações de contra-movimentos que vem agindo de forma a bloquear propostas progressistas (SZWAKO, 2014 apud ZAREMBERG; ALMEIDA, no prelo).

Segundo Pecheny et al. (2016), em alguns países, atores religiosos tem uma influência direta no eleitorado e no voto. Esta atuação religiosa está presente tanto no campo parlamentar quanto no judiciário, campo este que também é uma estratégia usada pelos movimentos feministas para garantir os seus direitos (SÁEZ; FAÚNDES, 2016). Isso tem tornado "invisíveis as mulheres e identidades e práticas sexuais alternativas perante instituições legais projetadas para proteger os indivíduos" ((SÁEZ; FAÚNDES, 2016, p.8)8.

\footnotetext{
7 Tradução livre do espanhol: “Contribuyeron a esto la afinidad de muchos militantes con fuerzas de izquierda, el apoyo más homogéneo de sectores progresistas a reformas similares o la idea de que serían gobiernos más sensibles a responder en temas de igualdad" (PÉREZ BENTANCUR \& ROCHA CARPIUC, no prelo, p. 24).

8 Tradução livre do espanhol: "[...] invisibles a las mujeres y a las identidades y prácticas sexuales alternativas ante las instituciones jurídicas concebidas para proteger a los individuos" (SÁEZ \& FAÚNDES, 2016, p. 8).
} 
Assim, as igrejas estão cada vez mais presentes nos debates relacionados às leis, principalmente aquelas em que para eles estão ligadas ou interferem nas práticas e costumes da religião, ou, como eles denominam, na "ordem moral objetiva". Vaggione (2016) alerta para o fato de que esta influência das igrejas na formulação das leis é o principal obstáculo para avanços de direitos sexuais e reprodutivos e para a ação dos movimentos feministas.

Pelo fato de a secularização ser um processo incompleto em boa parte da região, a Igreja Católica conta com privilégios formais e materiais para poder influenciar tanto a aprovação como a aplicação das mais variadas leis (VAGGIONE, 2016). Segundo Vaggione (2016), o poder da Igreja Católica na região também está relacionado às constantes crises dos governos destes países. O autor continua apontando que os políticos têm pouca autonomia, e passam a precisar do apoio desta instituição, que conta com altos e estáveis índices de confiança junto à população, em uma região que é marcada por uma herança católica. Há, então, uma troca de apoio entre a Igreja e os governos - na qual as instituições religiosas exercem grande autoridade junto ao Estado -, o que garante à primeira a capacidade de defender a moralidade sexual.

No México, entretanto, não é possível ver de forma clara essa relação aprofundada entre as instituições políticas e as religiosas. O México é considerado um país secular, o que favoreceu o desenvolvimento do ativismo feminista, enquanto nota-se um ativismo religioso conservador enfraquecido (ZAREMBERG, 2020). O país é um dos poucos na América Latina em que a separação entre Estado e igreja, além de ser definida na Constituição do país - como em outros países da região -, mostra que é realmente seguida. Desde a sua primeira constituição, em 1857, o México não faz referência a nenhuma organização religiosa. Mas não apenas isso, há um forte componente anticlerical nas matérias, podendo ser citados a laicidade da educação pública, a limitação de atividades religiosas católicas, a negativa de 
garantir personalidade jurídica às entidades religiosas e o impedimento de que os partidos políticos fizessem qualquer referência religiosa.

Como exemplo disso, não é possível a criação de partidos ligados diretamente ou provenientes de denominações religiosas ${ }^{9}$. Como as igrejas não podem interferir diretamente em atividades políticas no México, os movimentos conservadores se utilizaram indiretamente das estruturas eclesiais para gerar mobilizações em torno dos seus interesses, o que permitiu o acesso às elites econômicas e sociais que frequentam esses espaços e que têm grande influência junto aos partidos. Desta forma, esses movimentos conseguem mobilizar uma grande quantidade de pessoas (ZAREMBERG, 2020).

É em 2018 que se vê um ativismo mais frequente dos setores conservadores mexicanos, momento em que impulsionaram a Frente Nacional para a Família, na ocasião em que se era debatido, no Legislativo, o reconhecimento do casamento igualitário para casais LGBTs. Com isso, se observa que tais movimentos vem ganhando cada vez mais espaço nas instituições políticas (ZAREMBERG, 2020).

É, principalmente nas questões de direito sexual e reprodutivo, que se verificam mais confrontos entre as igrejas e os movimentos feministas. Esse embate é observado no Brasil, de forma mais clara, a partir do final da década de 1980, na formulação da nova Constituição. No período da Constituinte havia a demanda, por parte dos movimentos feministas, da legalização do aborto. Esta demanda acabou sendo suprimida após lobby e mobilização da Igreja Católica junto aos representantes do chamado "centrão".

Isso nos revela que essa relação não está presente apenas nos governos de partidos conservadores, mas também dos progressistas (VAGGIONE, 2016). Exemplos disso são a Nicarágua e o Equador - sob

\footnotetext{
${ }_{9}$ Apenas recentemente, com o surgimento do PES - Partido Encontro Social em 2014, que se observa uma relação mais direta de grupos religiosos, no caso dos neopentecostais, na política mexicana. $\mathrm{O}$ partido declarava abertamente que era ligado a denominações evangélicas. Posteriormente o partido perdeu o seu registro por não ter conseguido o número mínimo de votos.
} 
os governos de Ortega e Correa, respectivamente. Ambos são governos considerados progressistas - sendo que o governo de Ortega apenas no início do seu mandato -, que fizeram acordos com a Igreja Católica, evitando alterações de leis em questões de sexualidade. O Brasil também é um exemplo a ser citado. Durante os governos do PT constata-se uma aliança entre esse partido e grupos conservadores da sociedade brasileira. Para ilustrar, em 2003 as denominações neopentecostais passam a fazer parte da coalizão formada pelo Presidente Lula e em 2009 se observa um primeiro ativismo pentecostal no lançamento do Programa Nacional de Direitos Humanos (PNDH). Posteriormente se nota a influência dos mesmos durante as campanhas eleitorais de 2010 e 2014 (CAMPOS MACHADO, 2016), sempre buscando inserir a visão religiosa neste campo.

Mesmo apresentando avanços em questões como a representação política e a melhoria nas condições sociais das mulheres mais pobres, os governos de esquerda da América Latina, segundo Friedman e Tabbush (2019), dependeram de relações heteropatriarcais de poder, não executando diversas políticas que alterariam mais profundamente o cenário desigual da região. Alianças entre as forças políticas progressistas e forças religiosas conservadoras são, segundo Friedman e Tabbush (2019), importantes para compreender as políticas que foram implementadas na região neste período.

Além do mais, é com o aumento da presença nos legislativos de políticos que possuíam uma identificação religiosa, que crescem as denúncias de grupos feministas contra as interferências de grupos religiosos nas políticas de gênero. Isso leva Campos Machado (2016, p. 166) a apontar que "parecem ter entorpecido a possibilidade de estabelecer relações mais estreitas entre os setores protestantes e os movimentos de direitos humanos na região" 10 .

10 Tradução livre do espanhol: “[...] parecen haber entorpecido la posibilidad de establecer relaciones más estrechas entre los sectores protestantes y los movimientos de derechos humanos en la región [...]" (CAMPOS MACHADO, 2016, p. 166). 
Tanto no Brasil como no México se percebe esse incremento na quantidade de políticos que se identificam com as demandas dos setores conservadores, principalmente ligados às religiões, mas é possível que neste último não tão profundamente como no primeiro. Segundo Campos Machado (2016), ao observar o crescimento de projetos legislativos que remetiam a temas como a despenalização do aborto e a legislação dos direitos LGBT, os integrantes dessas religiões perceberam a necessidade de sua presença nos legislativos nacionais.

Contudo, esta capacidade das igrejas em influenciar nos debates em torno das questões sexuais e reprodutivas pode variar de um contexto para o outro. Como exemplo, no México, grupos católicos apoiam o casamento entre pessoas do mesmo sexo, contudo, ainda apresentam obstáculos em relação a liberação de alguns direitos reprodutivos (SÁEZ; FAÚNDES, 2016). No Brasil, os setores evangélicos conservadores são forças políticas e sociais cada vez mais importantes, utilizando-se do discurso em torno dos direitos humanos - partindo-se de uma reelaboração desta ideia - para se oporem aos direitos sexuais e reprodutivos (CAMPOS MACHADO, 2016).

Ainda, é possível perceber que muitas instituições religiosas foram aliadas importantes para se avançar em políticas de igualdade social, mesmo que estas mesmas instituições se opusessem quando a questão era a autonomia reprodutiva ou direitos LGBT. Sendo assim, a mudança dependeria da "força de partidos religiosos ou coalizões e a dinâmica de cooperação e conflito entre a liderança do poder Executivo e atores conservadores ou religiosos" (FRIEDMAN; TABBUSH, 2019, p. 10)11. Já Lind (2019, p. 11)12 argumenta que “em alguns países, por exemplo, mais direitos foram estendidos às mulheres e/ou às pessoas

\footnotetext{
11 Tradução livre do inglês: "strength of religious parties or coalitions and the dynamics of cooperation and conflict between the leadership of the executive branch and conservative or religious actors" (FRIEDMAN; TABBUSH, 2019, p. 10).

12 Tradução livre do inglês: "in some countries, for example, more rights were extended to women and/or LGBT people during the neoliberal period than during the more recent socialist period" (LIND, 2019, p.11).
} 
LGBT durante o período neoliberal do que durante o período socialista mais recente".

A literatura sobre o assunto aponta que as relações patriarcais e a influência das Igrejas são pontos importantes a serem considerados ao se analisar as políticas que são aprovadas nos legislativos. Tanto o Brasil quanto o México apresentam uma sociedade patriarcal que pode servir de barreira para que certas políticas de gênero sejam adotadas. Já em relação à influência de denominações religiosas, se observa que no Brasil há uma aproximação entre as igrejas e atores políticos, o que não parece ser claramente observado no México. Podendo considerar que a questão secular pode ser diferente entre esses dois países selecionados.

\section{Considerações finais}

O foco da análise deste trabalho estava na abertura ou não do debate em torno de políticas para as mulheres, a partir da relação entre governos diferentes com movimentos sociais antagônicos. Como é possível perceber, as relações mantidas tanto pelo Estado brasileiro quanto o mexicano com os movimentos feministas e os conservadores podem ser decisivas para a atuação em políticas de igualdade de gênero.

Como Weldon (2002), se afirmou que o movimento feminista tem um papel importante para a representação feminina, uma vez que ele pode aumentar a capacidade do Estado em atuar para tal questão. No Brasil, o que se observa é que este movimento teve suas demandas ouvidas, se voltou cada vez mais para o Estado, principalmente se fazendo uso de espaços participativos e cargos no Estado. Contudo, a aproximação com o PT mostrou, em alguns momentos, certos traços de conflito e inércia. No México, observa-se que as feministas ocuparam, no período analisado, as três esferas de poder. No nível federal, o que se destaca é a influência das redes de ativistas feministas, servindo como 
obstáculo13 para a aprovação de políticas que retiravam direitos das mulheres. Além disso, a atuação junto ao Judiciário é a principal marca destes movimentos nesse país.

Como mencionado anteriormente, os grupos conservadores, principalmente aqueles vinculados às igrejas, estão se mostrando, cada vez mais, o principal obstáculo para que políticas de gênero sejam aprovadas. Observou-se que no México a influência desses grupos não se mostrou tão relevante no período estudado. A prática usada pelos conservadores mexicanos era gerar mobilizações, se utilizando das estruturas das denominações religiosas para ter acesso a atores importantes. Apenas recentemente, período não abarcado pela pesquisa, que se observa um fortalecimento de grupos conservadores no país, passando a possuir mais influência no campo político e atuando contra algumas políticas de gênero. No caso brasileiro, se observa que o PT se aliou a grupos conservadores com o objetivo de conservar a coalizão de governo e manter a presidência. Isso garantiu a esses grupos certa influência nesse governo, o que se reverteu em ativismo poderoso contra políticas mais progressistas de gênero.

Vale salientar que ao focarmos nos movimentos feministas e conservadores, não descartamos, contudo, a existência de uma gama de variáveis que também podem sinalizar para esta aparente diferença entre as políticas para as mulheres propostas nestes dois países, podendo se revelar mais decisivas.

\section{Referências}

BLOFIELD, Merike; EWIG, Christina. The Left Turn and Abortion Politics in Latin America, Social Politics, v. 24, n. 4, p. 481-510, 2017.

CAMPOS MACHADO, Maria das Dores. Pentecostales y controversias de los derechos humanos en Brasil. In: SÁEZ, Macarena; FAÚNDES, José Manuel Morán (Ed.). Sexo, Delitos y Pecados: Intersecciones entre

13 No Brasil também se observa esta atuação dos movimentos feministas mais como obstáculo a determinadas políticas, como a Lei do Nascituro. 
religión, género, sexualidad y el derecho en América Latina. Washington, DC: Center for Latin American \& Latino Studies, 2016. p. 161- 193.

CELIS, Karen; CHILDS, Sarah. Introduction: The "puzzle" of gender, conservatism and representation. In: CELIS, Karen; CHILDS, Sarah (Ed.). Gender, conservatism and political representation. ECPR Press, 2014. p. 1-20.

FRIEDMAN, Elizabeth J.; TABBUSH, Constanza. Contesting the Pink Tide. In: FRIEDMAN, Elizabeth J. (Ed.). Seeking Rights from the Left. Gender, Sexuality, and the Latin American Pink Tide. Durham and London: Duke University Press, 2019.

HTUN, Mala; WELDON, Laurel. When Do Governments Promote Women's Rights? A Framework for the Comparative Analysis of Sex Equality Policy. Perspectives on Politics, v. 8, n. 1, p. 207-216, 2010.

IBARRA GARCÍA, Verónica; DAMÍAN BERNAL, Angélica Lucía. Mujeres en el Legislativo Federal, una mirada espacial Méxco 19882011. Revista Latino-americana de Geografía e Gêreno, Ponta Grossa, v. 4, n. 1, p. 2-13, jan./jul. 2013.

LIND, Amy. Foreword. In: FRIEDMAN, Elizabeth J. (Ed.), Seeking Rights from the Left. Gender, Sexuality, and the Latin American Pink Tide. Durham and London: Duke University Press, 2019.

MARQUES, Danusa. Determinantes de carreiras políticas no Brasil, na Argentina e no Uruguai: uma abordagem comparativa entre deputadas e deputados. 2012. Tese (Doutorado em Ciência Política) Universidade Federal de Minas Gerais, Belo Horizonte, 2012.

MATOS, Marlise. Gênero e sexualidade nas políticas públicas: O temor de retrocesso. Teoria e Debate, v. 149, 2016.

PECHENY, Mario; JONES, Daniel; ARIZA, Lucía. Sexualidad, política y actores religiosos en la Argentina post-neoliberal (2003-2015). In: SÁEZ, Macarena; FAÚNDES, José Manuel Morán (Ed.). Sexo, Delitos y Pecados: Intersecciones entre religión, género, sexualidad y el derecho en América Latina. Washington, DC: Center for Latin American \& Latino Studies, 2016.

PÉREZ BENTANCUR, Verónica; ROCHA CARPIUC, Cecilia. Derechos de las mujeres y diversidad sexual en los gobiernos del giro a la 
izquierda. In: Jorge Lanzaro (comp.). Balance del giro a la izquierda en América Latina. Montevideo, no prelo.

PINHEIRO, Marina Brito. Sobre a relação entre os movimentos feministas e o estado no Brasil (2003-2014). 2015. Tese (Doutorado em Ciência Política) - Faculdade de Filosofia e Ciências Humanas, Universidade Federal de Minas Gerais, Belo Horizonte, 2015.

POGREBINSCHI, Thamy; SANTOS, Fabiano. Participação como representação: o impacto das conferências nacionais de políticas públicas no Congresso Nacional. Dados, Rio de Janeiro, v. 54, n. 3, p. 259-305.

RODRÍGUES GUSTÁ, Ana Laura; MADERA, Nancy; CAMINITTI, Mariana. Governance Models of Gender Policy Machineries under Left and Right Governments in Latin America. Social Politics, v. 24, n. 4, p. 452-480, 2017.

RODRÍGUES GUSTÁ, Ana Laura; MADERA, Nancy. Organizational Repertoires for Advancing Women's Rights: An Analysis of Structures, Groups and Policies in National Legislatures in Latin America and the Caribbean. In: DOSEK, Tomáš Došek, CAMINOTTI, Mariana; FREIDENBERG, Flavia; MUÑOZ-POGOSSIAN, Betilde (Ed.). Women, Politics and Democracy in Latin America. New York: Palgrave, 2016. p. 89-106.

SÁEZ, Macarena; FAÚNDES, José Manuel Morán (Ed.). Sexo, Delitos y Pecados: Intersecciones entre religión, género, sexualidad y el derecho en América Latina. Washington, DC: Center for Latin American \& Latino Studies, 2016.

VAGGIONE, Juan Marco. Sexualidade, direito e religião: webites na tensão. In: SÁEZ, Macarena; FAÚNDES, José Manuel Morán (Ed.). Sexo, Delitos y Pecados: Intersecciones entre religión, género, sexualidad y el derecho en América Latina. Washington, DC: Center for Latin American \& Latino Studies, 2016. p. 161- 193.

WELDON, Laurel S. Beyond bodies: Institutional sources of representation for women in democratic policymaking. Journal of Politics, v. 64, n. 4, p. 1153-74, 2002.

WELDON, S. Laurel. When protest makes policy: how social movements represent disadvantaged groups. University of Michigan, 2011. 
ZAREMBERG, Gisela; ALMEIDA, Debora. Participative ecologies and feminist activisms in Mexico and Brazil (2000-2018), no prelo.

ZAREMBERG, Gisela; GUZMÁN LUCERO, Fernando. Aborto, movimientos y femocracias: un análisis relacional. Revista Mexicana de Sociología, v. 81, n. 1, p. 145-177, 2019.

ZAREMBERG, Gisela. Feminism and Conservatism in México. Politics \& Gender, v. 16, n. 1, 2020. 